\title{
Strength Training for Arthritis Trial (START): design and rationale
}

\author{
Stephen P Messier ${ }^{1,3,10^{*}}$, Shannon L Mihalko ${ }^{1}$, Daniel P Beavers ${ }^{2}$, Barbara J Nicklas ${ }^{3,1}$, Paul DeVita ${ }^{4}$, J Jeffery Carr ${ }^{5}$, \\ David J Hunter ${ }^{6}$, Jeff D Williamson ${ }^{3}$, Kim L Bennell ${ }^{7}$, Ali Guermazi ${ }^{8}$, Mary Lyles ${ }^{3}$ and Richard F Loeser ${ }^{9,1}$
}

\begin{abstract}
Background: Muscle loss and fat gain contribute to the disability, pain, and morbidity associated with knee osteoarthritis $(\mathrm{OA})$, and thigh muscle weakness is an independent and modifiable risk factor for it. However, while all published treatment guidelines recommend muscle strengthening exercise to combat loss of muscle mass and strength in knee OA patients, previous strength training studies either used intensities or loads below recommended levels for healthy adults or were generally short, lasting only 6 to 24 weeks. The efficacy of high-intensity strength training in improving OA symptoms, slowing progression, and affecting the underlying mechanisms has not been examined due to the unsubstantiated belief that it might exacerbate symptoms. We hypothesize that in addition to short-term clinical benefits, combining greater duration with high-intensity strength training will alter thigh composition sufficiently to attain long-term reductions in knee-joint forces, lower pain levels, decrease inflammatory cytokines, and slow OA progression.
\end{abstract}

Methods/Design: This is an assessor-blind, randomized controlled trial. The study population consists of 372 older (age $\geq 55$ yrs) ambulatory, community-dwelling persons with: (1) mild-to-moderate medial tibiofemoral OA (Kellgren-Lawrence $(\mathrm{KL})=2$ or 3); (2) knee neutral or varus aligned knee ( $-2^{\circ}$ valgus $\leq$ angle $\leq 10^{\circ}$ varus); (3) $20 \mathrm{kgm}^{-2} \geq$ $\mathrm{BMI} \leq 45 \mathrm{~kg} \mathrm{~m}^{-2}$; and (3) no participation in a formal strength-training program for more than 30 minutes per week within the past 6 months. Participants are randomized to one of 3 groups: high-intensity strength training (75-90\% 1Repetition Maximum (1RM)); low-intensity strength training (30-40\%1RM); or healthy living education. The primary clinical aim is to compare the interventions' effects on knee pain, and the primary mechanistic aim is to compare their effects on knee-joint compressive forces during walking, a mechanism that affects the OA disease pathway. Secondary aims will compare the interventions' effects on additional clinical measures of disease severity (e.g., function, mobility); disease progression measured by $\mathrm{x}$-ray; thigh muscle and fat volume, measured by computed tomography (CT); components of thigh muscle function, including hip abductor strength and quadriceps strength, and power; additional measures of knee-joint loading; inflammatory and OA biomarkers; and health-related quality of life.

Discussion: Test-retest reliability for the thigh $C T$ scan was: total thigh volume, intra-class correlation coefficients $(I C C)=0.99$; total fat volume, ICC $=0.99$, and total muscle volume, ICC $=0.99$. ICC for both isokinetic concentric knee flexion and extension strength was 0.93 , and for hip-abductor concentric strength was 0.99 . The reliability of our $1 \mathrm{RM}$ testing was: leg press, ICC $=0.95$; leg curl, ICC $=0.99$; and leg extension, ICC $=0.98$. Results of this trial will provide critically needed guidance for clinicians in a variety of health professions who prescribe and oversee treatment and prevention of OA-related complications. Given the prevalence and impact of OA and the widespread availability of this intervention, assessing the efficacy of optimal strength training has the potential for immediate and vital clinical impact.

Trial registration: ClinicalTrials.gov, NCT01489462

\footnotetext{
* Correspondence: messier@wfu.edu

'Department of Health and Exercise Science, Wake Forest University,

Winston-Salem, NC 27109, USA

${ }^{3}$ Section on Gerontology and Geriatric Medicine, Wake Forest School of

Medicine, Winston-Salem, NC, USA

Full list of author information is available at the end of the article
}

\section{Biomed Central}

(c) 2013 Messier et al.; licensee BioMed Central Ltd. This is an Open Access article distributed under the terms of the Creative Commons Attribution License (http://creativecommons.org/licenses/by/2.0), which permits unrestricted use, distribution, and reproduction in any medium, provided the original work is properly cited. 


\section{Background}

By 2030, an estimated 67 million American adults will report physician-diagnosed arthritis-a $40 \%$ increase in 25 years [1]. Osteoarthritis (OA) is the most common form of arthritis and the leading cause of disability among adults; the prevalence of self-reported doctor diagnosed OA in the United States is estimated at greater than 27 million persons [2]. Knee OA accounts for a significant portion of this disability, and is largely due to factors that alter knee-joint loading. Results from this project will inform future management of patients suffering from knee OA and could have enormous public health implications.

Muscle loss and fat gain contribute to the disability, pain, and morbidity associated with knee OA [3], and thigh muscle weakness is an independent, modifiable risk factor $[4,5]$. While treatment guidelines recommend strengthening exercise to combat sarcopenia in knee OA patients $[6,7]$, the appropriate intensities or loads (defined as percent of one repetition maximum, or \%1RM) recommended are unclear. The intensities used in previous OA studies were below those recommended by the American College of Sports Medicine for healthy adults [8] (60-80\% 1RM). Further, the programs were generally short, between 6 and 24 weeks [9-16]; effect sizes were low-to-modest, changes in progression could not be detected, and they provided little lasting clinical benefit. Indeed, short-term exercise benefits are gone 6 months post-exercise [17-19] but longterm supervised exercise results in sustained benefits 2 years after the treatment ends [20]. Few have studied the effectiveness of more intense strength training due to the unsubstantiated belief that it might exacerbate OA symptoms [21]. Preliminary studies indicate that high-intensity strength training is safe and well tolerated by healthy older adults [22,23] and knee OA patients [16,24].

Greater thigh fat is associated with obesity, a major risk factor for knee OA [25]. Obesity combined with sarcopenia, termed sarcopenic obesity, is also closely associated with the prevalence of knee OA with an Odds Ratio $=3.51$ [26]. Intensive strength training can change thigh composition in older adults and has shown promise in treating the underlying biomechanical (knee-joint loading) and inflammatory disease pathways. Studies in healthy older adults associate intensive strength training with increased fat-free thigh mass and quadriceps crosssectional area and decreased percent body fat and thigh subcutaneous fat with minimal alteration in total body weight [27-30]. Sipila and Suominen [27] and Ferri et al. [23] noted increased quadriceps cross-sectional area and lean cross-sectional area, and less intramuscular thigh fat after 16-18 weeks of intensive strength training. Similarly, Treuth et al. [31-33] found increased thigh muscle mass and decreased thigh fat mass after 16 weeks of high-intensity strength training in older men and women. High-intensity strength training also reduced interleukin
(IL)-18, a pro-inflammatory cytokine, in HIV-infected patients [34] and IL-6 and C-reactive protein (CRP) levels in older adults with chronic kidney disease compared to controls [35]. We must now gather clinical and mechanistic evidence to determine if improved thigh muscle composition has long-term protective effects on joint mechanics, inflammation, and structural progression in knee OA.

This paper describes the design of the Strength Training for ARthritis Trial (START), the first long-term clinical trial comparing the efficacy of high- (75-90\% 1RM) to low-intensity (30-40\% 1RM) strength training and Healthy Living Education interventions in older adults with knee OA. This trial is designed to identify potential mechanisms, (i.e. knee joint loading and systemic inflammation) responsible for any changes in pain, function, and mobility consequent to intensive strength training. We expect initial improvements in thigh muscle function, pain, and knee-joint loading with high-intensity strength training after 6 months; 18 months will determine, for the first time, if further changes in thigh muscle function and composition significantly reduce knee-joint forces and inflammatory cytokines resulting in a greater decrease in pain and attenuated OA disease progression (Figure 1). Given the prevalence of OA, the detrimental effects of sarcopenia and obesity [26], and the safety and widespread availability of the intervention, this trial has immediate, potentially transformative clinical impact.

\section{Methods/Design \\ Study design}

START is an assessor-blinded, single-center, 18-month, parallel design randomized controlled trial. Participants are randomized into one of 3 groups: high-intensity strength training $(\mathrm{H})$, low-intensity strength training $(\mathrm{L})$, or healthy living education $(\mathrm{C})$.

\section{Study sample}

The study sample consists of 372 ambulatory, communitydwelling adults age $\geq 55$ yrs with self-reported disability due to knee OA. Inclusion criteria include: (1) mild-tomoderate radiographic medial tibiofemoral OA (KellgrenLawrence (KL) = 2 or 3); (2) knee neutral or varus aligned knee ( $-2^{\circ}$ valgus $\leq$ angle $\leq 10^{\circ}$ varus); (3) BMI $\geq 20 \mathrm{kgm}^{-2}$ and $\leq 45 \mathrm{kgm}^{-2}$; and (4) no participation in formal strength training for more than 30 min wk $^{-1}$ in the past 6 months. We exclude people with BMI $>45 \mathrm{~kg}^{-2}$ because of difficulty in using $\mathrm{CT}$ equipment and lower adherence to exercise [36,37] and $<20 \mathrm{~kg} \cdot \mathrm{m}^{-2}$ because of limited thigh fat. We include only people with neutral $\left(-2^{\circ}\right.$ valgus to $2^{\circ}$ varus) or moderate varus $\left(\leq 10^{\circ}\right.$ varus $)$ alignment and medial knee OA and not predominant lateral compartment or severe patellofemoral (PF) compartment disease because (1) the medial compartment is the most common disease site, and (2) medial progression is strongly associated 


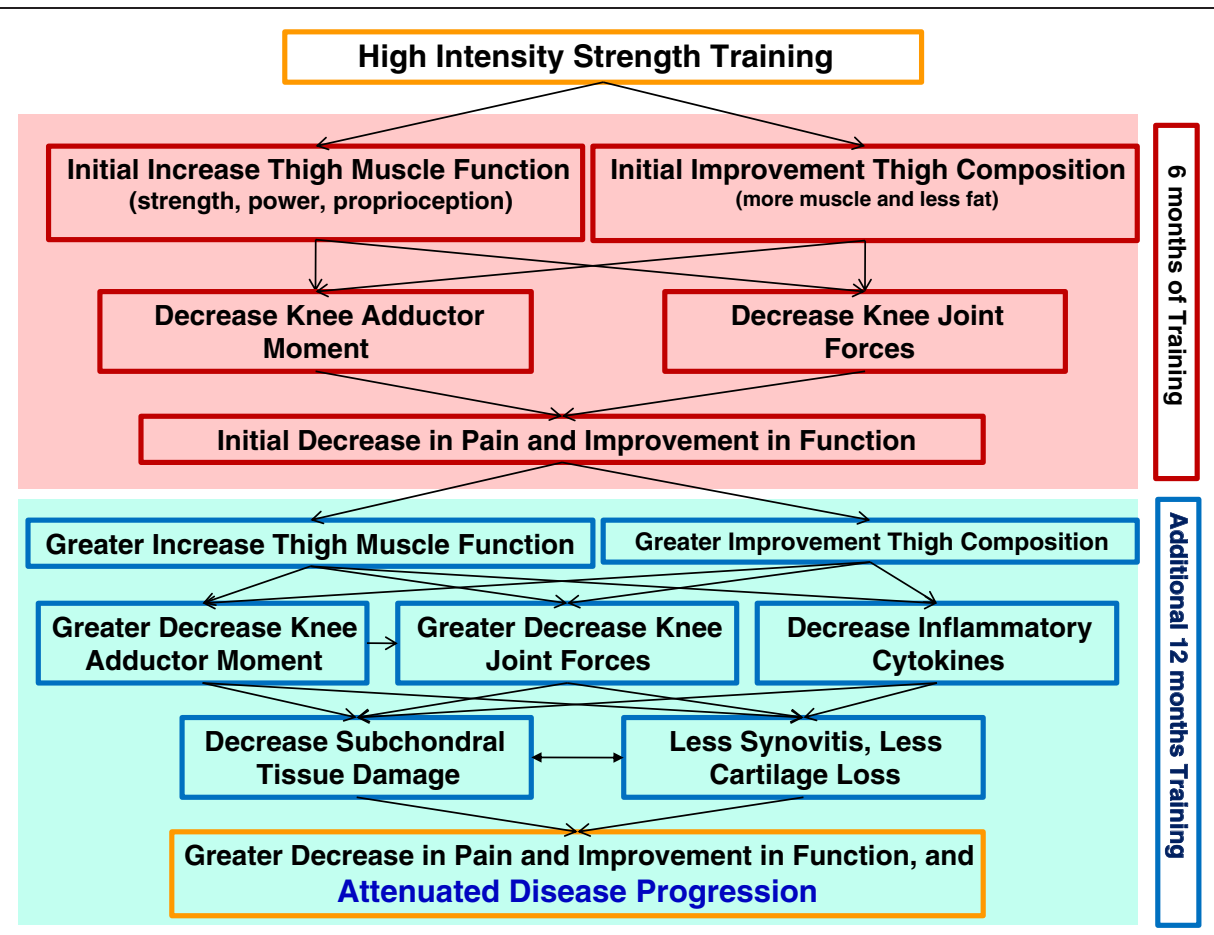

Figure 1 Hypothesized pathways mediating high-intensity strength-training outcomes at 6 and 18 mos.

with moderate varus alignment [38-40], independent of BMI [41]. People with extreme malalignment ( $>10$ degrees varus) might experience greater progression in a strengthening program [21,42]. Medial bone-marrow lesions are seen mostly in patients with varus limbs, who are most likely to progress medially [43]. This approach will engage an enriched cohort of structural progressors to determine better our intervention's ability to slow the disease [16]. All participants may maintain their medications, including NSAIDs. If pain decreases, they may reduce them with their physician's consent. Medication use is recorded at baseline and 6-, 12-, and 18-month follow-up testing. Exclusion criteria are listed in Table 1 . The study protocol was reviewed and approved by the Human Subjects Committee of Wake Forest University Health Sciences (Human Protocol: IRB00018176) and is in compliance with the terms and conditions set forth in the Helsinki Declaration (http://www.wma.net/en/30publications/10policies/ b3/index.html). Informed consent will be obtained from all study participants.

\section{Interventions}

\section{Strength training}

Both strength training interventions consist of a 5-min warm-up, 40-min training, and 15-min cool-down. The 60-min sessions are conducted 3 times $^{\prime} \mathrm{wk}^{-1}$ for 18 months at the Wake Forest Clinical Research Center. Each group session will include between 12-24 participants (1 to 2 waves) and will be supervised by two American College of
Sports Medicine certified exercise interventionists and a number of undergraduate interns. The first two sessions introduce participants to proper techniques, and at the third, 1-repetition max (1RM) tests determine the starting resistance used for each exercise in the subsequent sessions until the next assessment (detailed below). Intensity (load) is defined as \%1RM [8]. The reliability of our 1RM testing for 12 older adults with knee OA tested twice one week apart was: leg press, $\mathrm{ICC}=0.95$; leg curl, $\mathrm{ICC}=0.99$; and leg extension, $\mathrm{ICC}=0.98$. Each exercise is performed on a Nautilus resistance-training machine with $60-90 \mathrm{~s}$ of rest between sets; 1RM is defined as the maximum weight one can lift in a single repetition. Participants will keep a session log of each resistance exercise, its weight setting, and number of sets and repetitions achieved. Although our hypotheses focus on the lower extremity, experience indicates that participants want a well-rounded program. Thus, for both groups the program includes 6 lower body exercises with each leg exercised separately to prevent an unequal distribution of load between the least affected and most affected sides: hip abduction and adduction; leg curl, extension, and press; and seated calf; and 4 upper body and core exercises: compound row, vertical chest, lower back, and abdomen. We use Nautilus machines based on time, safety, and availability, but results will be generalizable to most strength training methods. Participants perform a 5 minute warm-up on either the walking track or a stationary bicycle and, at the completion of each strength training session, a 15 minute cool-down 


\begin{tabular}{|c|c|c|}
\hline Criteria & Exclusion & Method \\
\hline $\begin{array}{l}\text { Significant co-morbid disease that would threaten safety } \\
\text { or impair ability to participate in interventions or testing, } \\
\text { previous acute knee injury, bilateral severe tibiofemoral } \\
\text { OA, severe patellofemoral OA (JSN = } 3 \text { using OARSI atlas), } \\
\text { no definite medial tibiofemoral OA, severe obesity, low } \\
\text { weight. }\end{array}$ & $\begin{array}{l}\text { Symptomatic or severe coronary artery disease; } \\
\text { severe HTN; active cancer other than skin cancer; } \\
\text { anemia; dementia; liver disease; COPD; peripheral } \\
\text { vascular disease; inability to walk without an } \\
\text { assistive device; blindness; type } 1 \text { diabetes; type } 2 \\
\text { diabetes on thiazolidinedione agents; bilateral } \\
\text { severe medial tibiofemoral } \mathrm{OA}(\mathrm{KL}=4) \text {, no definite } \\
\text { medial tibiofemoral OA }(\mathrm{KL}=0,1), \mathrm{BMI}<20 \text { or } \\
>45 \mathrm{~kg} \mathrm{~m}^{-2}\end{array}$ & $\begin{array}{l}\text { Medical history; physical exam; } \\
\text { PA and skyline knee x-ray; height } \\
\text { and weight. }\end{array}$ \\
\hline $\begin{array}{l}\text { OA disease location and alignment restrictions: } \\
\text { predominant knee OA other than medial tibiofemoral OA; } \\
\text { valgus, or extreme varus alignment. }\end{array}$ & $\begin{array}{l}\text { Lateral tibiofemoral } \mathrm{OA}>\text { medial tibiofemoral } \mathrm{OA} \text {, } \\
\text { severe patellofemoral } \mathrm{OA} \text {; valgus knee alignment } \\
>2^{\circ} \text {, or varus alignment }>10^{\circ}\end{array}$ & $\begin{array}{l}\text { Knee PA and skyline view } x \text {-rays, } \\
\text { lower extremity long } x \text {-ray. }\end{array}$ \\
\hline Excess alcohol use & $\geq 21$ drinks per week & Questionnaire \\
\hline $\begin{array}{l}\text { Inability to finish 18-month study or unlikely to be } \\
\text { compliant }\end{array}$ & $\begin{array}{l}\text { Lives }>50 \text { miles from site or planning to leave } \\
\text { area } \geq 3 \text { months during the next } 18 \text { months }\end{array}$ & Questionnaire, interview \\
\hline Conditions that prohibit $\mathrm{CT}$ & $\mathrm{BMI}>45 \mathrm{~kg} \mathrm{~m}^{-2}$ & height and weight \\
\hline Significant cognitive impairment & diagnosis of dementia or a MoCA score $<20$ & Medical history, MoCA \\
\hline Low Pain & Pain $\leq 3$ on a scale from $0-20$ & WOMAC \\
\hline
\end{tabular}

consisting of various upper and lower body stretching exercises.

Participants who plan absences of $>2$ sessions use Thera-Bands in a home-based program. Upon their return, interventionists determine the progression needed to reach prior intensity.

Previous strength training trials with older adults predict small fluctuations in body weight $(<1 \mathrm{~kg})$ as muscle mass increases and fat mass decreases [44]. Interventionists are alert to any substantial change $(\geq 2 \mathrm{~kg})$ and, if necessary, the participant is referred to the medical director.

\section{High-intensity intervention $(H)$}

The $\mathrm{H}$ group performs 3 sets of each exercise at $75-90 \%$ of $1 \mathrm{RM}$, within the intensity range necessary to maximize muscular hypertrophy [8]. Each block has the following structure and is repeated with training loads recalibrated to each new 1RM:

Weeks $1-2.3$ sets by 8 reps. Intensity: 75\% of 1RM Weeks $3-4$. 3 sets by 8 reps. Intensity: $80 \%$ of 1 RM Weeks $5-6$. 3 sets by 6 reps. Intensity: $85 \%$ of 1 RM Weeks $7-8$. 3 sets by 4 reps. Intensity: $90 \%$ of $1 R M$ Week 9. Taper. Alternate exercises and 1RM testing

Most participants have no difficulty progressing at 2 -wk intervals, but variation is inevitable. Participants will rate perceived exertion (RPE) at completion of each workout. On a 10-point Borg category ratio-RPE scale, the $\mathrm{H}$ group should be working between 5 (hard)-8 (very hard), and the L group between 2 (easy)-4 (somewhat hard) [45]. At the end of each block, we add taper periods-2 days (Monday, Friday) of alternate exercises using Thera-Bands, separated by a 1RM testing day (Wednesday) - because the use of Thera-Bands has been shown to increase performance in older women [46].

\section{Low-intensity intervention ( $L$ )}

The L group performs 3 sets of 15 repetitions at 30-40\% of 1RM using the exercises described above. Each 8 -week block has the following structure:

Weeks $1-2.3$ sets by 15 reps. Intensity: $30 \%$ of 1 RM. Weeks $3-4.3$ sets by 15 reps. Intensity: $35 \%$ of 1 RM. Weeks 4-6. 3 sets by 15 reps. Intensity: $40 \%$ of 1 RM. Weeks $7-8.3$ sets by 15 reps. Intensity: $35 \%$ of 1 RM.

Week 9. Taper week. Alternate exercises and 1RM testing

Repeat weeks 1-8 with training loads recalibrated to each new 1RM.

The workloads for the $\mathrm{H}$ and $\mathrm{L}$ groups are equated (Table 2).

\section{Healthy living education}

The control group is modeled after the Arthritis Diet and Activity Promotion Trial's (ADAPT) healthy lifestyle comparison group [47], providing attention, social interaction, and health education. Participants attend 60-min organized workshops bi-weekly for the first 6 months and monthly thereafter. This arm aims to control for attention from study staff and general levels of participant time; to encourage recruitment, adherence and benefit; and not to influence the primary outcomes directly: no evidence suggests that health education alone will affect pain or knee-joint loads during walking. The decision to use a tapered schedule is based on careful consideration of science, adherence, and expense. The control group is 
Table 2 Sample workloads and total volume for high- and low-intensity interventions, assuming 1RM = 100 lbs

\begin{tabular}{|c|c|c|}
\hline Intervention & Sets/Repetitions/Intensity & Volume \\
\hline \multicolumn{3}{|l|}{ Low Intensity } \\
\hline Weeks 1-2 & 3 sets of 15 reps at 30\% 1-RM & $45 \mathrm{reps}^{*} 30 \mathrm{lbs}=1350 \mathrm{lbs}^{*} 2 \mathrm{wks}=2700 \mathrm{lbs}$ \\
\hline Weeks 3-4 & 3 sets of 15 reps at $35 \%$ 1-RM & 45 reps $^{*} 35 \mathrm{lbs}=1575 \mathrm{lbs}^{*} 2 \mathrm{wks}=3150 \mathrm{lbs}$ \\
\hline Weeks 5-6 & 3 sets of 15 reps at $40 \%$ 1-RM & $45 \mathrm{reps}^{*} 40 \mathrm{lbs}=1800 \mathrm{lbs}^{*} 2 \mathrm{wks}=3600 \mathrm{lbs}$ \\
\hline Weeks 7-8 & 3 sets of 15 reps at $35 \%$ 1-RM & $45 \mathrm{reps}^{*} 35 \mathrm{lbs}=1575 \mathrm{lbs}^{*} 2 \mathrm{wks}=3150 \mathrm{lbs}$ \\
\hline Weeks 1 thru 8 & & Total volume $=12600 \mathrm{lbs}$ \\
\hline \multicolumn{3}{|l|}{ High Intensity } \\
\hline Weeks 1-2 & 3 sets of 8 reps at $75 \% 1-\mathrm{RM}$ & $24 \mathrm{reps}^{*} 75 \mathrm{lbs}=1800 \mathrm{lbs}^{*} 2 \mathrm{wks}=3600 \mathrm{lbs}$ \\
\hline Weeks 3-4 & 3 sets of 8 reps at $80 \% 1-\mathrm{RM}$ & $24 \mathrm{reps}^{*} 80 \mathrm{lbs}=1920 \mathrm{lbs}^{*} 2 \mathrm{wks}=3840 \mathrm{lbs}$ \\
\hline Weeks 5-6 & 3 sets of 6 reps at $85 \% 1-\mathrm{RM}$ & 18 reps $^{*} 85 \mathrm{lbs}=1530 \mathrm{lbs}^{*} 2 \mathrm{wks}=3060 \mathrm{lbs}$ \\
\hline Weeks 7-8 & 3 sets of 4 reps at $90 \% 1-\mathrm{RM}$ & 12 reps $^{*} 90 \mathrm{lbs}=1080 \mathrm{lbs}^{*} 2 \mathrm{wks}=2160 \mathrm{lbs}$ \\
\hline \multirow[t]{2}{*}{ Weeks 1 thru 8} & & Total volume $=12660 \mathrm{lbs}$ \\
\hline & & Low/High Ratio $=1.0$ \\
\hline
\end{tabular}

Total volume $=$ total repetitions $*$ intensity $*$ resistance (assume $100 \mathrm{lbs}$ ).

not matched hour-for-hour to the intervention groups but reflects the way community health-education programs are typically offered and the observation that older adults are less likely to attend more often.

Over the 18 months, interactive presentations cover such topics as hearing loss, nutrition, managing medication, and sleep practices, and experts will give wideranging lectures. An experiential component encourages participants to seek more information about their health and related practices. They are asked to complete homework, review topics, and engage in small group discussions to increase their involvement in this study arm. Each workshop ends with seated upper body stretching to enhance adherence and increase perceived benefit without directly affecting the knees or study outcomes. Prior studies suggest older adults are less likely to participate if they think any treatment group does not provide personal benefit.

\section{Techniques to improve adherence and retention}

Time-intensive behavioral studies require significant commitment [47-49]. START's design evolved from social cognitive theory (SCT), group dynamics, and over 22 years' experience in randomized controlled trials: our 18-month trials Fitness Arthritis and Seniors Trial (FAST), ADAPT, and Intensive Diet and Exercise for Arthritis (IDEA) had between $80 \%-88 \%$ retention and $58-70 \%$ adherence. We estimate $80 \%$ retention and $65 \%$ adherence rates over the intervention; adherence is calculated by dividing the total number of sessions completed by the number scheduled.

START interventionists are trained by our health psychologist in standardized behavioral techniques developed in a SCT framework. They include frequent contact during the intervention; positive feedback; incentives to reach attendance and performance goals; establishing personal commitment to the project; and targeted mechanisms for behavioral adherence, including self-efficacy, outcome expectations, and self-regulatory skills. The importance of regular attendance is emphasized with study participants on an ongoing basis. Adherence data are reviewed regularly to identify any participants who need additional reminders and/or counseling. Our toolbox approach, guided by algorithms of common strategies and decision-making processes, tailors the intervention to each participant's needs. For example, if a participant misses two consecutive sessions and has no contact with the interventionist, a phone session is scheduled. The interventionist assesses participant study goals and barriers to participation. Together, participant and interventionist develop a specific plan. Collectively, these strategies increase social cognitive mechanisms for regular participation and enhanced adherence in all groups.

\section{Trial conduct}

\section{Recruitment}

The 30-month recruitment period is divided into 10 waves of approximately 37 participants each, entering the study at 3-month intervals. The predominant recruitment strategy is newspaper advertisements. Other recruitment efforts include mass mailings, presentations at local aging service networks, senior centers, churches, radio, and online advertising. Our Claude D. Pepper Older Americans Independence Center recruitment core also has access to a large database of older adults who have consented to be contacted about participation in clinical trials. Specific strategies aim to maximize the number of African Americans who qualify for, and are enrolled in, the study. At biweekly meetings, all recruitment activities and the number of participants randomized are reviewed. 


\section{Measurements}

\section{Screening and follow-up visits}

Those who are eligible after prescreening (PSV) sign an informed consent and attend 2 screenings (SV) and a randomization visit (RV). All 372 participants are measured at baseline, 6-, 12-, and 18-month follow-ups (FU) (Figure 2 and Table 3 ).

\section{Screening}

The Eligibility Questionnaire addresses joint pain, physical function, activity level, co-morbid diseases, willingness to participate for 18 months, height and weight (to determine $\mathrm{BMI}$ ), caregiver status, status of significant others, and distance of home from the center (within 50-mile radius). A study physician and a physician assistant perform routine medical exams. A score of $<20$ on the Montreal Cognitive
Assessment (MoCA) [50,51] will justify exclusion because cognitively impaired persons may not be able to adhere to the protocol; persons scoring $>17$ on the Center for Epidemiologic Studies Depression scale (CES-D) [52] are evaluated by the study physician, who determines eligibility.

\section{Western Ontario McMasters Universities Osteoarthritis Index (WOMAC)}

Self-reported pain (primary clinical outcome) and physical function are measured using the Likert version of WOMAC [53]. The pain index assesses participants' pain on a scale, ranging from 0 (none) to 4 (extreme). The pain subscale consists of 5 items and total scores can range from $0-20$, with higher scores indicating greater pain. This instrument is recommended by the Osteoarthritis Research Society International as the health status measure of choice

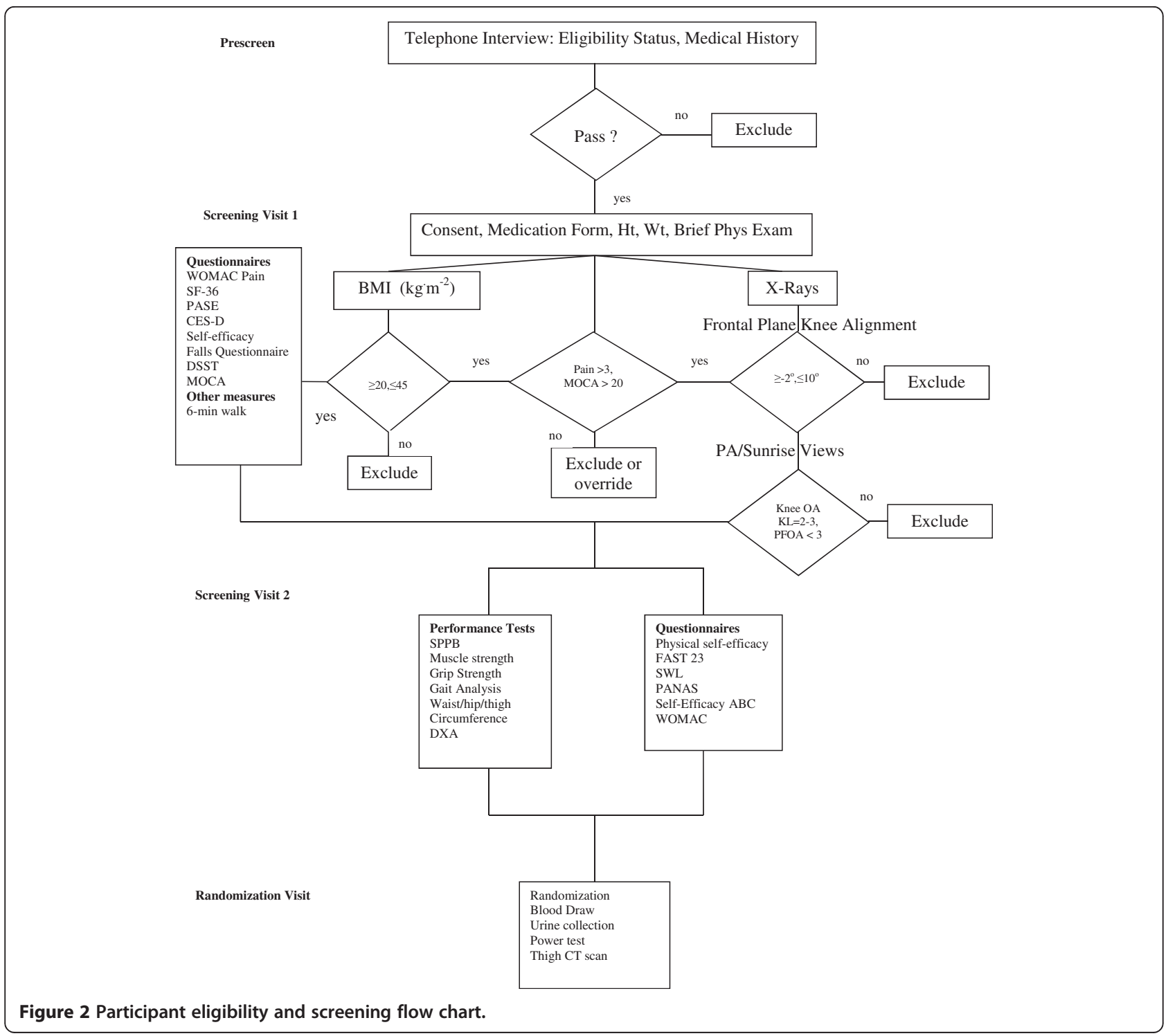


Table 3 Data-collection visits

\begin{tabular}{|c|c|c|c|c|c|c|c|}
\hline Measurements & PSV & SV1 & SV2 & RV & FU6 & FU12 & FU18 \\
\hline randomization & & & & $x$ & & & \\
\hline informed consent & & $x$ & & & & & \\
\hline eligibility questionnaire & $x$ & & & & & & \\
\hline medical history & $x c$ & $x$ & & & $x$ & $x$ & $x$ \\
\hline WOMAC & & $x$ & $x$ & & $x$ & $x$ & $x$ \\
\hline PASE scale & & $x$ & & & $x$ & $x$ & $x$ \\
\hline MoCA & & $x$ & & & $x$ & $x$ & $x$ \\
\hline CES-D & & $x$ & & & $x$ & $x$ & $x$ \\
\hline SF-36 (general health, quality life) & & $x$ & & & $x$ & $x$ & $x$ \\
\hline Self Efficacy & & $x$ & & & $x$ & $x$ & $x$ \\
\hline 6-min walk & & $x$ & & & $x$ & $x$ & $x$ \\
\hline Demographics & & $x$ & & & & & \\
\hline Brief physical exam & & $x$ & & & & & \\
\hline Medication Form & & $x$ & & & $x$ & $x$ & $x$ \\
\hline Knee A-P x-ray & & $x$ & & & & & $x$ \\
\hline Knee $x$-ray skyline view & & $x$ & & & & & \\
\hline Full length lower extremity $x$-ray & & $x$ & & & & & \\
\hline height & $x c$ & $x$ & & & & & \\
\hline weight & $x c$ & $x$ & & & $x$ & $x$ & $x$ \\
\hline Waist/Hip circumference & & & $x$ & & $x$ & $x$ & $x$ \\
\hline DXA & & & $x$ & & & & $x$ \\
\hline CT scans: thigh & & & & $x$ & & & $x$ \\
\hline Biomarkers: blood & & & & $x$ & & & $x$ \\
\hline Biomarkers: urine & & & & $x$ & $x$ & & $x$ \\
\hline Gait Analysis & & & $x$ & & $x$ & & $x$ \\
\hline Muscle function tests: Power, Strength & & & $\mathrm{x}$ & & $x$ & $\mathrm{x}$ & $x$ \\
\hline
\end{tabular}

for older adults with knee OA. It has been validated for use in orthopaedic and pharmacologic interventions [53,54]. The pain subscale will be used only as a screening tool during SV1 (pain must be $>3$ ). It will also be administered to the eligible participants at SV2 and each scheduled followup visit.

For physical function, the Likert version asks participants to indicate on the same scale from 0 (none) to 4 (extreme) the degree of difficulty experienced performing activities of daily living in the last 48 hours due to knee OA. Individual scores for the 17 items are totaled to generate a summary score that can range from 0-68, with higher scores indicating poorer function.

\section{Gait}

The primary mechanistic outcome is maximal knee compressive force; secondary outcomes include internal knee abduction moment and AP shear force [55-59]. A 25-reflective marker set, 6-camera Motion Analysis System $(100 \mathrm{~Hz})$, and 2, 6-channel force plates (AMTI, Newton, MA. $1000 \mathrm{~Hz}$ ) obtain 3D kinematic and kinetic gait data. The former will be acquired using Cortex 3.0 software
(Motion Analysis Corporation, Santa Rosa, CA) and a Butterworth low-pass filter (6 Hz cutoff). For each participant, 3 successful trials are analyzed; i.e., within $\pm 3.5 \%$ of the participant's freely chosen speed, and the entire foot must contact the force plate in a visually normal stride. Smoothed coordinate data, ground reaction, and gravitational and inertial forces will inform an inverse dynamics model to calculate 3D moments and forces at the hip, knee, and ankle joints using Visual 3D Standard 4.0 clinical gait analysis software (C-Motion, Germantown, MD). These moments and forces will be used in the knee model developed by DeVita et al. [60] for use in knee OA subjects $[58,59]$. Model-predicted knee-compression force was also a primary outcome in IDEA. Our testretest reliability intraclass correlations (ICC) for 21 knee OA patients with mean age 65.7 yrs $(\mathrm{SD}=5.8)$ were $\mathrm{r}=0.86$ for internal peak knee extensor moment, $\mathrm{r}=0.94$ for internal peak abductor moment, and $\mathrm{r}=0.95$ for peak knee compressive force [61]. A detailed explanation of our model can be found elsewhere [62].

Numerous biomechanical-neuromuscular models exist that predict knee joint forces during locomotion. Many 
of these models predict highly similar results, strengthening the confidence researchers have in these models [63-65]. True biomechanical model validation is difficult and most predicted results have not been compared to measured knee joint forces, a gold standard for model validation. Recently, Fregly et al. [66] have made available measured in vivo knee joint force data during walking along with all pertinent biomechanical data for the purpose of validating biomechanical models predicting knee joint loads. These data come from individuals with instrumented knee joint prostheses and are available through the website, https://simtk.org/home/kneeloads. We used their biomechanical gait data as input for our model to predict knee joint forces from five walking trials and then compared our results to Fregly's actual measured values from the same subjects. Our predicted values were highly similar to the measured values with the predicted first and second maximum compressive forces within $7 \%$ and $3 \%$ of the observed values, respectively (Figure 3 ).

\section{Mobility}

Our measure of mobility is 6-min walk distance, with a 3-month test-retest reliability of 0.86 [67].

\section{Health-Related Quality of Life (HRQL)}

The SF-36 [68] is the most widely used and carefully validated measure of HRQL. It yields two broad summary scores: physical health and mental health.

\section{Body composition}

Dual-energy x-ray absorptiometry (DXA) (GE Healthcare iDXA Digital Densitometry) is used for measurements of bone mineral density (BMD) and body tissue composition including whole body changes in total fat (FM) and lean (LM) mass [69-71]. Percent coefficients of variation (\%CV) are $1.2 \%$ for whole body FM; $0.5 \%$ for whole body LM;

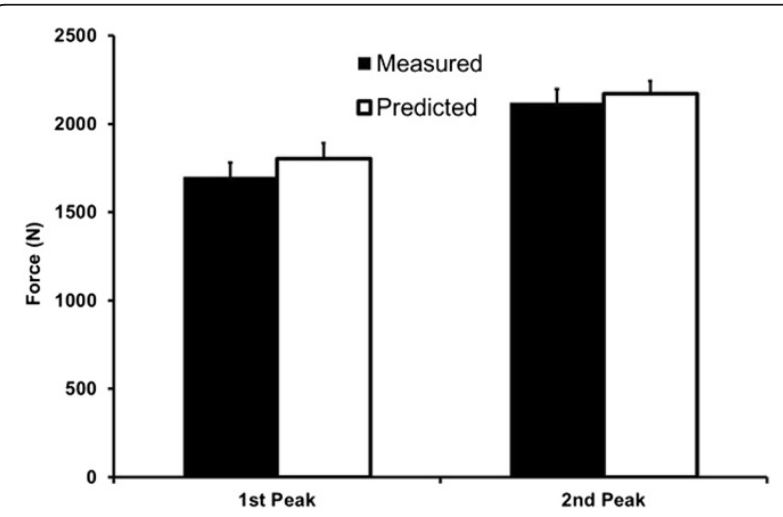

Figure 3 Comparison of peak knee compressive forces derived from our musculoskeletal model (predicted) using Fregly et al. data as input, and the measured value from an instrumented prostheses (measured) of the same subjects.
0.9\% for whole body BMD; $1.2 \%$ for posterioranterior (PA) spine BMD; and $0.9 \%$ for total hip BMD.

\section{Thigh composition}

A secondary outcome is the measurement of thigh skeletal muscle and adipose tissue using volumetric noncontrast enhanced computer tomography (CT) (VCT 64, GE Healthcare Waukesha, WI). Participants will be placed supine on the CT couch with their legs held in a neutral position by dedicated Velcro straps. A calibration phantom (Image Analysis, Columbia, KY) with known CT densities for fat, water, and calcium is placed in the scan fields of view (FOV) posterior to the legs. A 2-dimensional topogram is obtained covering from the pelvis to the knees. A single helical scan series is performed starting at the femoral head and ending below the knee joint in the tibial plateau. Technique for the scan includes: helical mode, 120 $\mathrm{KV}, 150 \mathrm{mAs}$, with reconstruction of both legs at $5 \mathrm{~mm}$ slice thickness and $50 \mathrm{~cm}$ display field of view (DFOV). Additional reconstructions are performed using the same exposure to the participant to obtain sets of images using thinner slices $(1.25 \mathrm{~mm}$ and $0.625 \mathrm{~mm})$ using both standard and bone kernels to optimize image quality. Each femur has a set of high-resolution $30-\mathrm{cm}$ dfov targets for potential future analysis of cortical bone structure.

\section{CT image analysis software and protocol}

The topogram of the femur is measured from the greater tuberosity of the femur to the inferior aspect of the medial femoral condyle. This length is trisected, and the junction between the proximal and mid-third is the landmark for measurement. Measurements of right and left thigh composition are performed using the slices that start at the location $25 \mathrm{~mm}$ above and the end $25 \mathrm{~mm}$ below this point, providing a sampling length of $50 \mathrm{~mm}$ along the long axis of the femur (e.g. head to foot). CT images are analyzed (reader masked to treatment group) on a medical imaging workstation with custom plugins to measure the volume of the entire thigh, thigh musculature, and intermuscular fat. Test-retest reliability on the thigh CT scans of a quality control sample of START participants $(n=10)$ re-analyzed an average of 3.7 months apart was: total thigh volume, $\mathrm{ICC}=0.99$; total fat volume, $\mathrm{ICC}=0.99$, and total muscle volume, ICC $=0.99$.

\section{Blood and urine sample collection}

Blood samples (50 ml per visit) for assessing biomarkers are collected via venipuncture at a specific time in the morning at least 2 hours after rising and after a 10-hour overnight fast at baseline and at 6- and 18-month assessment visits. Urine samples (second am void, $20 \mathrm{ml}$ per visit) are collected in $250 \mathrm{ml}$ specimen cups by each participant for analysis of new and emerging OA biomarkers. Serum, plasma, and urine are aliquoted and stored at $-80^{\circ} \mathrm{C}$ 
until analysis of our pre-chosen biomarkers (see below) at the end of the study. Aliquots are also stored long-term to test for promising new inflammatory and OA biomarkers that may become available after the study.

\section{Inflammatory markers}

IL-6, tumor necrosis factor-alpha (TNF $\alpha)$, and soluble TNF receptor 1 (sTNFR1) were chosen for their known implication in OA [72-77]. They have been shown to change with 1 year of moderate strength training [78]. IL-6 is our primary inflammation measure. All inflammatory marker assays are performed in the WFSM ELISA Core Laboratory. All samples are measured in duplicate, using the average for analyses. Commercially available (R\&D Systems, Minneapolis, MN) enzyme-linked immunosorbent assay (ELISA) kits are used: high-sensitivity Quantikine ${ }^{\circledast}$ for IL-6. In our laboratory, inter- and intra-assay coefficients of variation (CV) for IL-6 are $5.4 \%$ and $3.5 \%$, respectively; for TNF $\alpha, 11.8 \%$ and $6.2 \%$, respectively; and under $5 \%$ for the soluble receptor assays

\section{OA Biomarkers}

There is a lack of gold standard biomarkers for OA and so the choice of biomarkers that will be measured will be based on the most recent findings available at the completion of the trial. Possible markers could include serum COMP (AnaMar Medical, Uppsala, SW) and urine markers of collagen degradation such as C2C-HUSA (Ibex Technologies, Montreal, CN).

\section{Muscle function tests}

Strength Knee flexion/extension concentric strength is assessed at baseline, 6, 12, and 18 months using a Humac NORM isokinetic dynamometer (Computer Sports Medicine Inc, Stoughton, MA) set to $30 \mathrm{deg}^{-1}$. Strength testretest reliability for 10 participants tested twice in our lab, 7-10 days apart, had an ICC of 0.93 for both concentric knee flexion and extension strength. Since we suggest that intensive strength training can reduce knee-joint loads by counterbalancing the external knee-adductor moment with strong hip abductors, we also measure hip-abductor concentric strength at $30 \mathrm{degs}^{-1}(\mathrm{ICC}=0.99)$. Knee strength is measured with the participant in a seated position; hip abductor strength is measured in a side lying position.

Power The Nottingham power rig is used to measure bilateral leg extensor power because it correlates well with such functional measures as chair-rise, stair-climbing, and walking speed in elderly subjects [79]. This measurement is safe and acceptable for all age groups $[79,80]$.

\section{Medications}

A questionnaire adapted from the Atherosclerosis Risk In Communities (ARIC) [81] study and widely used in field research and our studies is designed to obtain information (during SV1 and FU visits) about all prescription and over-the-counter medicines and supplements used during the 2 weeks prior to interview.

\section{$X$-ray}

Bilateral PA weight-bearing knee $\mathrm{x}$-rays using a positioning device (SynaFlexer ${ }^{\mathrm{T}}$, Synarc Inc., San Francisco, CA) and the modified Lyon-Schuss technique [82] are used to identify tibiofemoral (TF) OA and skyline views to identify PF OA. The former is repeated at 18 months to assess changes in joint-space width (JSW). Radiographs are evaluated using the K-L score of 0-4 to assess disease severity as we have described and we include only participants with a score of 2 or 3 in at least one knee ( $\mathrm{KL}$ score $=4$ is acceptable in the contralateral knee). We exclude people with severe PF OA (JSN $=3$ on a $0-3$ scale using the OARSI atlas) and control for severity (none-to-moderate) in statistical analyses. We define medial TF disease based on our previous definitions [83], and participants with lateral $>$ medial joint space narrowing are excluded.

The knee PA protocol includes positioning the participant standing and facing the Bucky or cassette holder with the $x$-ray beam centered on the joint line angulated caudally 10 degrees. The $x$-ray is repeated at 5 and 15 degrees and the most acceptable image (based upon alignment of the medial tibial plateau) is used for analysis. Criteria include good contrast/exposure, optimal visualization of the articular surfaces with the floor of the medial tibial plateau clearly delineated, and both knee joints included and centered on the film.

To assess alignment, a full-length AP radiograph of each lower extremity is obtained at baseline with participants positioned following Sharma et al. [84]. Mechanical alignment is the measure of the angle formed by the intersection of the lines connecting the centers of the femoral head and intercondylar notch and the centers of the ankle talus and tibial spines, with neutral angles between $0-2^{\circ}$ varus, varus knee angles $>2^{\circ}$ inward, and valgus angles $>0^{\circ}$ outward. The range of eligible knee angles is $-2^{\circ}$ valgus to $10^{\circ}$ varus.

Disease progression is defined as change in x-ray medial TF JSW. A physician, masked to treatment group, measures JSW using automated computerized software. The software automatically delineates the joint space contour with the help of an edge-based algorithm. The area of measurement of minimum JSW is defined by 2 vertical lines and 2 horizontal lines obtained by a single click on the nonosteophytic outer edge of the medial femoral condyle and a single click on the inner edge of the medial tibial plateau close to the articular surface. Within these landmarks, the delineation of the bone edges of the medial femoral condyle and medial tibial 
plateau floor, in addition to the minimum JSW, are automatically obtained [85].

\section{Additional questionnaires}

Physical Activity Scale for the Elderly (PASE) [86], Center for Epidemiologic Studies Depression Scale (CES-D) (92), and a self-efficacy for adherence measure [87] are used to assess physical activity, depression, and self-efficacy at baseline and follow-up. The Montreal Cognitive Assessment $(\mathrm{MoCA})$ is used to measure cognitive functioning at baseline; a score $\geq 20$ is required for study inclusion. The Digital Symbol Substitution Test (DSST) will be used to measure cognitive functioning.

\section{Adverse event collection and reporting}

An adverse event (AE) is defined as any unfavorable and unintended diagnosis, sign, symptom, or disease temporarily associated with the study intervention, which may or may not be related to the intervention. Non-serious AEs will be reported by the study staff to the project manager and principal investigator within 7 days of notification of the event. The study physician will review each non serious $\mathrm{AE}$ on a weekly basis that will be included in the NIAMS safety officer report that is submitted semi-annually. A serious AE (SAE) is any untoward medical occurrence that results in death, is lifethreatening, requires or prolongs hospitalization, causes persistent or significant disability/incapacity, results in congenital abnormalities, or represents other significant hazards or potentially serious harm to research participants or others. Study staff will report SAEs to the project manager, study physician, and the principal investigator within 24 hours of notification. NIAMS will be notified within 24 hours subsequent to notification of the principal investigator.

\section{Timeline}

Recruitment for each of 10 waves takes 3 months with an average of 37.2 participants/wave; an average of 12.4 participants are randomized/month for 30 months.

\section{Randomization}

A stratified block randomization with block size unknown to investigators and staff ensures equal accrual to each study arm. Prestratification balances pretrial BMI values (20.0-24.9, 25.0-29.9, 30.0-34.9, 35.0-39.9, 40.0-45.0 kg m${ }^{-2}$ ) and gender, which could predict intervention effect and associations between secondary outcome variables.

\section{Data management}

Data are collected on hard copy forms and transformed to an electronic database. We use a web-based management system to assure integrity and validity. Dynamic reports and periodic statistical analyses monitor quality.
A participant-based inventory system tracks recruitment, retention, adherence, and missing data from entry through exit, close-out, and lock-down of final datasets. Our team developed a similar database for the IDEA study.

\section{Statistical considerations Statistical analyses}

All primary analyses are based on the intention-to-treat method in which each participant is included in the initial randomization group regardless of adherence. START stratification factors, baseline BMI, and gender are included in all statistical models, so the analysis matches the design, and the estimated variance is not biased. Assumptions are verified for all models, and appropriate transformations used when necessary.

Primary aim The primary aim is the treatment effect on knee pain and maximal compressive force at 18 months. These and all other repeated measures continuous outcomes will be assessed using a mixed effects model including time (6 and 18 months), treatment group, the time $\times$ treatment interaction, and further adjusted for gender, baseline BMI, and baseline values of the outcome (i.e., baseline knee pain for knee pain model, baseline compressive force for compressive force model). The treatment effects at 18 months are tested by applying contrast statements to the mixed model, and maximumlikelihood techniques will be used to estimate parameters under the assumption of an $\mathrm{AR}(1)$ covariance structure. Each primary outcome will be analyzed at the Bonferroni-adjusted 0.025 level of significance, and pairwise comparisons between intervention groups at 18 months will use a 0.0083 two-sided level of significance (2 outcomes, 3 interventions) [88]. Preliminary analyses are conducted to check the shape of the distributions and variances between groups and as a function of the covariates to ensure residuals are approximately normally distributed. Regression diagnostics and residual plots help find appropriate transformations if necessary. In subsequent models, we will control for possible confounders, including PF OA severity (none to moderate) and use of medications, such as analgesics, NSAIDs, bisphosphonates, and glucosamine/chondroitin sulfate. Because we exclude subjects with severe PF OA and medication has only modest efficacy in OA, we do not expect significant confounding by these variables.

Secondary aims Standard repeated measures mixed models (including adjustment variables as noted above) are used for secondary aims at the 0.05 significance level, with pairwise treatment group comparisons performed at the 0.0167 significance level for testing 18 month effects. Short-term effects are determined by using contrast statements comparing 6-month treatment effect means 
from primary and secondary outcome models. Outcomes assessed at baseline and 18 months only (MoCa, DXA measures, and Knee PA x-ray) will be compared using an ANCOVA model for treatment effects adjusting for baseline BMI, gender, and baseline values of the outcome.

As inflammatory marker distributions are often skewed, data are log-transformed before analysis. The effect of the interventions at 18 months is determined with repeated measures mixed models and estimates obtained at each visit. For ease of interpretation, transformed log means and standard errors back to their original units are used.

Missing data If missing data are related to outcomes, our results will be slightly biased. Our models include variables from previous visits determined to predict loss to satisfy Little and Rubin's [89] conditions for data considered Missing at Random (MAR). If "informative censoring" occurs, we will compare analyses using participants with complete data, multiple imputations, or explicit modeling of the censoring mechanism $[90,91]$.

\section{Sample-size calculations}

Primary outcomes A total sample of 372 (124/group) provide $80 \%$ statistical power to detect differences $\geq 17.6 \%$ in pain and $\geq 9.6 \%$ in maximal compressive force at the 2-sided 0.0083 significance level with $80 \%$ retention (2-sample $t$-test, Nquery Advisor). Standard deviations for pain and maximal compressive force were obtained from the START pilot (unpublished) and ADAPT [58,59] which measured the same outcomes and used similar patient populations; with mean differences of 1.12 (18\%) and $657 \mathrm{~N}$ (20\%), respectively.

Secondary outcomes Overall, our sample size provides a moderate effect size of 0.46 with relevant detectable differences. ADAPT's largest effect on WOMAC function was a $17 \%$ relative decrease. We are able to detect differences in thigh-muscle volume smaller than 10\%. Goopaster [92] showed that after 12 months mean thigh-muscle attenuation significantly decreased by $1.4 \mathrm{HU}$ in a control group but not in a physical activity group. With 6 more months of physical activity, we expect to detect group differences as small as 2.3 HU. A magnitude of $22 \%$ reduction in IL-6 is similar to reductions seen in clinical trials of statins and other anti-inflammatory medications [93-98].

\section{Discussion}

Despite strong evidence for the potent effect of mechanics on disease progression and symptoms [55,99], there are few interventions that target mechanical load. One such intervention is strength training. However, many still believe that strength training for knee OA in general, and high-intensity strength training specifically, may exacerbate knee pain and be deleterious to joint structure. It is critical to evaluate the potential benefit (or harm) of commonly used therapeutic interventions such as strength training. Due to conflicting data it is unclear if an increase in the total joint reaction force occurring with muscle strengthening contraction may actually accelerate the progression of structural changes within the joint, rather than prevent it [100]. A longitudinal study of 79 women with radiographic knee OA found that the mean absolute quadriceps strength of women with progressive OA (defined as worsening of the Kellgren and Lawrence grade over 2.5 years) was about 9\% lower than those with radiographically stable OA [101]. In another observational study of 171 knee OA participants over 18 months, Sharma and colleagues [21] found that greater absolute quadriceps strength at baseline increased the risk of disease progression (defined as an increase in the grade of joint space narrowing in the medial or lateral compartment) in people with malaligned and lax knees (defined as $>5^{\circ}$ deviation from the mechanical axis) but not in those with neutral alignment. Since strength was not normalized for body mass, it is conceivable that the stronger participants were heavier, since absolute strength generally increases with body mass. More recently, Amin et al. [102] found no relationship between quadriceps strength and cartilage loss on MRI over 15 and 30 months anywhere except the lateral compartment of the patellofemoral joint, where increased quadriceps strength was protective against cartilage degeneration. Mikesky et al. [13] demonstrated a trend $(p=0.09)$ that strength training slowed joint space narrowing as measured on x-ray over 30 months in people with knee OA. It is important to recognize that they did not do intense training and did not elicit strength gains, just less strength loss, so different effects might be found in our study. Given the conflicting nature of the published literature and the public health impact of both a negative and a positive finding, the effects of strength training on pain, joint loading, and structure are critical to delineate.

There are several limitations and risks to our study. Our musculoskeletal model will estimate the knee joint compressive and shear forces. The principal limitations of most models are many simplifying assumptions about joint properties and structures that do not account for in-vivo symptoms and processes [39]. We have used our model extensively [58-60,103], and while it only estimates knee-joint biomechanics, the predictions for knee muscle and joint forces compare favorably with those of other predictive models, and are highly similar to measured forces from instrumented knee joint prostheses $[63,66,104,105]$. PF OA may also confound results. The symptoms in knee OA are frequently related to structural alterations in the PF joint, but despite great focus on the PF joint this relationship is relatively weak [106-108]. We will exclude people with severe PF OA 
(JSN $=3$, OARSI scale) and control for severity (none to moderate) in statistical analyses. Also measures of JSN by plain films may not be sensitive enough to detect differences in radiographic progression over 18 months unless the differences are large [109].

Risks to participants are small. Musculoskeletal injury may occur as the result of the exercise intervention, but during the strength-training portion of the recent IDEA trial of 454 overweight or obese subjects with knee OA, we had no serious injuries. We will include a blood pressure safety alert trigger for this study. The absolute contraindication to resistance training is set at greater than $180 / 110 \mathrm{mmHg}$, and the relative contraindication at above $160 / 100 \mathrm{mmHg}$. Bilateral volumetric measures of thigh adipose tissue and skeletal muscle will use a standard CT protocol. The thigh sequence is centered on the mid-thigh and is about $33 \%$ of the expected exposure of a clinical scan of this region. The average amount of radiation a person will receive is low, $3 \mathrm{mSv}$ (range 1.5-6 mSv). This value can be comparable to the U.S. average annual exposure from natural sources of $3 \mathrm{mSv}$ and lower than the $7 \mathrm{mSv}$ exposure of residents of Denver. The risk is comparable to, or less than, other risks encountered in daily life, such as driving or riding in a motor vehicle [110].

Given the prevalence and impact of OA and the widespread availability of strength training, assessing its efficacy has immediate and vital clinical impact. Results of this study will document accurately the effects of both high-and low-intensity strength training on knee joint pain, joint loads, inflammation, thigh composition, and disease progression, and provide critically needed guidance to clinicians who prescribe and oversee treatment and prevention of OA-related complications.

\section{Competing interests}

The authors declare that they have no competing interests.

\begin{abstract}
Authors' contributions
SPM conceived the study, participated in its design and coordination, carries out the biomechanical gait and strength analysis, and drafted the manuscript. SLM participated in its design, and coordinates patient compliance and adherence protocols. DPB participated in its design, coordinates statistical analyses and data management. BJN participated in its design and coordination, and carries out the biomarker analyses. PD participated in its design, helps coordinate the biomechanical gait analysis, and musculoskeletal modeling. JJC participated in its design, coordinates the $C T$ scans and analysis, and helps coordinate the x-ray exams. DJH participated in its design and helps to coordinate $x$-ray and $C T$ scan analyses. JDW participated in its design and is the medical director of the trial. $K L B$ participated in its design and helps coordinate the strength interventions and testing. AG designed the $x$-ray protocol and analysis of joint space width. ML carries out patient evaluations. RFL participated in its design, and coordinates $x$-ray reading, and carries out osteoarthritis biomarker analysis. All authors read and approved the final manuscript.
\end{abstract}

\section{Acknowledgements}

Support for this study was provided by grants from the National Institutes of Health: 1R01AR059105-01, P30 AG21332. The authors wish to acknowledge Jovita Newman for her many duties as project manager including coordinating the writing of the manual of operations.

\section{Author details}

'Department of Health and Exercise Science, Wake Forest University, Winston-Salem, NC 27109, USA. 'Department of Biostatistical Sciences, Wake Forest School of Medicine, Winston-Salem, NC, USA. ${ }^{3}$ Section on Gerontology and Geriatric Medicine, Wake Forest School of Medicine, Winston-Salem, NC, USA. ${ }^{4}$ Department of Exercise and Sport Science, East Carolina University, Greenville, NC, USA. ${ }^{5}$ Department of Radiology, Vanderbilt University Medical Center, Nashville, TN, USA. ${ }^{6}$ Rheumatology Department, Kolling Institute, University of Sydney, Sydney, Australia. 'Department of Physiotherapy, The University of Melbourne, Parkville, VIC, Australia. ${ }^{8}$ Department of Radiology, Boston University School of Medicine, Boston, USA. ${ }^{9}$ Section on Molecular Medicine, Wake Forest School of Medicine, Winston-Salem, NC, USA.

${ }^{10}$ Department of Rheumatology and Immunology, Wake Forest School of Medicine, Winston-Salem, NC, USA.

Received: 5 April 2013 Accepted: 11 June 2013

Published: 15 July 2013

\section{References}

1. Hootman JM, Helmick CG: Projections of US prevalence of arthritis and associated activity limitations. Arthritis Rheum 2006, 54:226-229.

2. Lawrence RC, Felson DT, Helmick CG, Arnold LM, Choi H, Deyo RA, et al: Estimates of the prevalence of arthritis and other rheumatic conditions in the United States: Part II. Arthritis Rheum 2008, 58:26-35.

3. Hurley BF, Roth SM: Strength training in the elderly: effects on risk factors for age-related diseases. Sports Med 2000, 30:249-268.

4. Hootman JM, Fitzgerald SJ, Macera CA, Blair SN: Lower extremity muscle strength and risk of self-reported hip or knee osteoarthritis. Journal of Physical Activity and Health 2004, 1:321-330.

5. Slemenda C, Brandt KD, Heilman DK, Mazzuca S, Braunstein EM, Katz BP, et al: Quadriceps weakness and osteoarthritis of the knee. Ann Intern Med 1997, 127:97-104.

6. American Academy of Orthopaedic Surgeons: Treatment of osteoarthritis of the knee (non-arthroplasty). American Academy of Orthopaedic Surgeons [2nd] 2008:19-20. 12-6-2008. Ref Type: Electronic Citation.

7. Zhang W, Moskowitz RW, Nuki G, Abramson S, Altman RD, Arden N, et al: OARSI recommendations for the management of hip and knee osteoarthritis, Part II: OARSI evidence-based, expert consensus guidelines. Osteoarthritis Cartilage 2008, 16:137-162.

8. Kraemer WJ, Adams K, Cafarelli E, Dudley GA, Dooly C, Feigenbaum MS, et al: Progression models in resistance training for healthy adults. Med Sci Sports Exerc 2002, 34:364-380.

9. Hurley MV, Scott DL: Improvements in quadriceps sensorimotor function and disability of patients with knee osteoarthritis following a clinically practicable exercise regime. Br J Rheumatol 1998, 37:1181-1187.

10. Maurer BT, Stern AG, Kinossian B, Cook KD, Schumacher HR Jr: Osteoarthritis of the knee: isokinetic quadriceps exercise versus an educational intervention. Arch Phys Med Rehabil 1999, 80:1293-1299.

11. O'Reilly SC, Muir KR, Doherty M: Effectiveness of home exercise on pain and disability from osteoarthritis of the knee: a randomised controlled trial. Ann Rheum Dis 1999, 58:15-19.

12. Petrella RJ, Bartha C: Home based exercise therapy for older patients with knee osteoarthritis: a randomized clinical trial. J Rheumatol 2000, 27:2215-2221.

13. Mikesky AE, Mazzuca SA, Brandt KD, Perkins SM, Damush T, Lane KA: Effects of strength training on the incidence and progression of knee osteoarthritis. Arthritis Rheum 2006, 55:690-699.

14. Thomas KS, Muir KR, Doherty M, Jones AC, O'Reilly SC, Bassey EJ: Home based exercise programme for knee pain and knee osteoarthritis: randomised controlled trial. BMJ 2002, 325:752.

15. Ettinger WH Jr, Burns R, Messier SP, Applegate W, Rejeski WJ, Morgan T, et al: A randomized trial comparing aerobic exercise and resistance exercise with a health education program in older adults with knee osteoarthritis. The Fitness Arthritis and Seniors Trial (FAST). JAMA 1997, 277:25-31.

16. King LK, Birmingham TB, Kean CO, Jones IC, Bryant DM, Giffin JR: Resistance training for medial compartment knee osteoarthritis and malalignment. Med Sci Sports Exerc 2008, 40:1376-1384.

17. van Baar ME, Dekker J, Oostendorp RA, Bijl D, Voorn TB, Bijlsma JW: Effectiveness of exercise in patients with osteoarthritis of hip or knee: nine months' follow up. Ann Rheum Dis 2001, 60:1123-1130. 
18. Bennell KL, Hunt MA, Wrigley TV, Lim BW, Hinman RS: Role of muscle in the genesis and management of knee osteoarthritis. Rheum Dis Clin North Am 2008, 34:731-754.

19. Pisters MF, Veenhof C, van Meeteren NL, Ostelo RW, de Bakker DH, Schellevis FG, et al: Long-term effectiveness of exercise therapy in patients with osteoarthritis of the hip or knee: a systematic review. Arthritis Rheum 2007, 57:1245-1253.

20. Rejeski WJ, Marsh AP, Chmelo E, Prescott AJ, Dobrosielski M, Walkup MP, et al: The Lifestyle Interventions and Independence for Elders Pilot (LIFE-P): 2-year follow-up. J Gerontol A Biol Sci Med Sci 2009, 64:462-467.

21. Sharma L, Dunlop DD, Cahue S, Song J, Hayes KW: Quadriceps strength and osteoarthritis progression in malaligned and lax knees. Ann Intern Med 2003, 138:613-619.

22. Caserotti $P$, Aagaard $P$, Larsen JB, Puggaard L: Explosive heavy-resistance training in old and very old adults: changes in rapid muscle force, strength and power. Scand J Med Sci Sports 2008, 18:773-782.

23. Ferri A, Scaglioni G, Pousson M, Capodaglio P, Van Hoecke J, Narici MV: Strength and power changes of the human plantar flexors and knee extensors in response to resistance training in old age. Acta Physio/ Scand 2003, 177:69-78.

24. Jan MH, Lin JJ, Liau JJ, Lin YF, Lin DH: Investigation of clinical effects of high- and low-resistance training for patients with knee osteoarthritis: a randomized controlled trial. Phys Ther 2008, 88:427-436.

25. Snijder MB, Dekker JM, Visser M, Bouter LM, Stehouwer CD, Yudkin JS, et al: Trunk fat and leg fat have independent and opposite associations with fasting and postload glucose levels: the Hoorn study. Diabetes Care 2004, 27:372-377.

26. Lee S, Kim TN, Kim SH: Sarcopenic obesity is more closely associated with knee osteoarthritis than is nonsarcopenic obesity: a cross-sectional study. Arthritis Rheum 2012, 64:3947-3954.

27. Sipila S, Suominen $\mathrm{H}$ : Effects of strength and endurance training on thigh and leg muscle mass and composition in elderly women. J Appl Physiol 1995, 78:334-340.

28. Sipila S, Suominen $\mathrm{H}$ : Muscle ultrasonography and computed tomography in elderly trained and untrained women. Muscle Nerve 1993, 16:294-300.

29. Klitgaard H, Mantoni M, Schiaffino S, Ausoni S, Gorza L, Laurent-Winter C, et al: Function, morphology and protein expression of ageing skeletal muscle: a cross-sectional study of elderly men with different training backgrounds. Acta Physiol Scand 1990, 140:41-54

30. Mikesky AE, Meyer A, Thompson KL: Relationship between quadriceps strength and rate of loading during gait in women. J Orthop Res 2000, 18:171-175.

31. Treuth MS, Hunter GR, Weinsier RL, Kell SH: Energy expenditure and substrate utilization in older women after strength training: 24-h calorimeter results. J Appl Physiol 1995, 78:2140-2146.

32. Treuth MS, Hunter GR, Kekes-Szabo T, Weinsier RL, Goran MI, Berland L: Reduction in intra-abdominal adipose tissue after strength training in older women. J Appl Physiol 1995, 78:1425-1431.

33. Treuth MS, Ryan AS, Pratley RE, Rubin MA, Miller JP, Nicklas BJ, et al: Effects of strength training on total and regional body composition in older men. J Appl Physiol 1994, 77:614-620.

34. Lindegaard B, Hansen T, Hvid T, van Hall G, Plomgaard P, Ditlevsen S, et al: The effect of strength and endurance training on insulin sensitivity and fat distribution in HIV-infected patients with lipodystrophy. J Clin Endocrinol Metab 2008, 93:3860-3869.

35. Castaneda C, Gordon PL, Parker RC, Uhlin KL, Roubenoff R, Levey AS: Resistance training to reduce the malnutrition-inflammation complex syndrome of chronic kidney disease. Am J Kidney Dis 2004, 43:607-616

36. Ekkekakis $P$, Lind E: Exercise does not feel the same when you are overweight: the impact of self-selected and imposed intensity on affect and exertion. Int J Obes (Lond) 2006, 30:652-660.

37. King AC, Kiernan M, Oman RF, Kraemer HC, Hull M, Ahn D: Can we identify who will adhere to long-term physical activity? Signal detection methodology as a potential aid to clinical decision making. Health Psychol 1997, 16:380-389.

38. Felson DT, Goggins J, Niu J, Zhang Y, Hunter DJ: The effect of body weight on progression of knee osteoarthritis is dependent on alignment. Arthritis Rheum 2004, 50:3904-3909.

39. Wilson DR, McWalter EJ, Johnston JD: The measurement of joint mechanics and their role in osteoarthritis genesis and progression. Rheum Dis Clin North Am 2008, 34:605-622
40. Chang A, Hayes K, Dunlop D, Song J, Hurwitz D, Cahue S, et al: Hip abduction moment and protection against medial tibiofemoral osteoarthritis progression. Arthritis Rheum 2005, 52:3515-3519.

41. Niu J, Zhang YQ, Torner J, Nevitt M, Lewis CE, Aliabadi $P$, et al: Is obesity a risk factor for progressive radiographic knee osteoarthritis? Arthritis Rheum 2009, 61:329-335.

42. Lim BW, Hinman RS, Wrigley TV, Sharma L, Bennell KL: Does knee malalignment mediate the effects of quadriceps strengthening on knee adduction moment, pain, and function in medial knee osteoarthritis? A randomized controlled trial. Arthritis Rheum 2008, 59:943-951.

43. Felson DT, McLaughlin S, Goggins J, LaValley MP, Gale ME, Totterman S, et al: Bone marrow edema and its relation to progression of knee osteoarthritis. Ann Intern Med 2003, 139:330-336.

44. Pratley R, Nicklas B, Rubin M, Miller J, Smith A, Smith M, et al: Strength training increases resting metabolic rate and norepinephrine levels in healthy 50- to 65-yr-old men. J App/ Physiol 1994, 76:133-137.

45. Day ML, McGuigan MR, Brice G, Foster C: Monitoring exercise intensity during resistance training using the session RPE scale. J Strength Cond Res 2004, 18:353-358.

46. Signorile JF, Carmel MP, Lai S, Roos BA: Early plateaus of power and torque gains during high- and low-speed resistance training of older women. J Appl Physiol 2005, 98:1213-1220.

47. Messier SP, Loeser RF, Miller GD, Morgan TM, Rejeski WJ, Sevick MA, et al: Exercise and dietary weight loss in overweight and obese older adults with knee osteoarthritis: the Arthritis, Diet, and Activity Promotion Trial. Arthritis Rheum 2004, 50:1501-1510.

48. van Gool CH, Penninx BW, Kempen Gl, Miller GD, van Eijk JT, Pahor M, et al: Determinants of high and low attendance to diet and exercise interventions among overweight and obese older adults. Results from the arthritis, diet, and activity promotion trial. Contemp Clin Trials 2006, 27:227-237.

49. Cyarto EV, Brown WJ, Marshall AL: Retention, adherence and compliance: important considerations for home- and group-based resistance training programs for older adults. J Sci Med Sport 2006, 9:402-412

50. Nasreddine ZS, Phillips N, Chertkow H: Normative data for the Montreal Cognitive Assessment (MoCA) in a population-based sample. Neurology 2012, 78:765-766.

51. Nasreddine ZS, Phillips NA, Bedirian V, Charbonneau S, Whitehead V, Collin I, et al: The Montreal Cognitive Assessment, MoCA: a brief screening tool for mild cognitive impairment. J Am Geriatr Soc 2005, 53:695-699.

52. Radloff LS: The CES-D scale: a self-report depression scale for research in the general population. Appl Psychol Meas 1977, 1:385-401.

53. Bellamy N, Buchanan WW, Goldsmith CH, Campbell J, Stitt LW: Validation study of WOMAC: a health status instrument for measuring clinically important patient relevant outcomes to antirheumatic drug therapy in patients with osteoarthritis of the hip or knee. J Rheumatol 1988, 15:1833-1840

54. Bellamy N, Buchanan WW, Goldsmith CH, Campbell J, Stitt L: Validation study of WOMAC: a health status instrument for measuring clinically important patient relevant outcomes following total hip or knee arthroplasty in osteoarthritis. Journal of Orthopaedic Rheumatology 1988, 1:95-108.

55. Andriacchi TP, Mundermann A: The role of ambulatory mechanics in the initiation and progression of knee osteoarthritis. Curr Opin Rheumatol 2006, 18:514-518.

56. Baliunas AJ, Hurwitz DE, Ryals AB, Karrar A, Case JP, Block JA, et al: Increased knee joint loads during walking are present in subjects with knee osteoarthritis. Osteoarthritis Cartilage 2002, 10:573-579.

57. Sharma L, Hurwitz DE, Thonar EJ, Sum JA, Lenz ME, Dunlop DD, et al: Knee adduction moment, serum hyaluronan level, and disease severity in medial tibiofemoral osteoarthritis. Arthritis Rheum 1998, 41:1233-1240.

58. Messier SP, Devita P, Cowan RE, Seay J, Young HC, Marsh AP: Do older adults with knee osteoarthritis place greater loads on the knee during gait? a preliminary study. Arch Phys Med Rehabil 2005, 86:703-709.

59. Messier SP, Gutekunst DJ, Davis C, Devita P: Weight loss reduces knee-joint loads in overweight and obese older adults with knee osteoarthritis. Arthritis Rheum 2005, 52:2026-2032.

60. Devita $\mathrm{P}$, Hortobagyi T: Functional knee brace alters predicted muscle and joint forces in people with $\mathrm{ACL}$ reconstruction during walking. J App Biomech 2001, 17:297-311.

61. Messier SP, Legault C, Mihalko S, Miller GD, Loeser RF, Devita P, et al: The Intensive Diet and Exercise for Arthritis (IDEA) trial: design and rationale. BMC Musculoskelet Disord 2009, 10:93. 
62. Messier SP, Legault C, Loeser RF, VanArsdale SJ, Davis C, Ettinger WH, et al: Does high weight loss in older adults with knee osteoarthritis affect bone-on-bone joint loads and muscle forces during walking? Osteoarthritis and Cartilage 2011, 19:272-280.

63. Lin YC, Walter JP, Banks SA, Pandy MG, Fregly BJ: Simultaneous prediction of muscle and contact forces in the knee during gait. J Biomech 2010, 43:945-952.

64. Kim HJ, Fernandez JW, Akbarshahi M, Walter JP, Fregly BJ, Pandy MG: Evaluation of predicted knee-joint muscle forces during gait using an instrumented knee implant. J Orthop Res 2009, 27:1326-1331.

65. Winby CR, Lloyd DG, Besier TF, Kirk TB: Muscle and external load contribution to knee joint contact loads during normal gait. J Biomech 2009, 42:2294-2300

66. Fregly BJ, Besier TF, Lloyd DG, Delp SL, Banks SA, Pandy MG, et al: Grand challenge competition to predict in vivo knee loads. J Orthop Res 2012, 30:503-513.

67. Penninx BW, Messier SP, Rejeski WJ, Williamson JD, DiBari M, Cavazzini C et al: Physical exercise and the prevention of disability in activities of daily living in older persons with osteoarthritis. Arch Intern Med 2001, 161:2309-2316.

68. Ware JE Jr, Sherbourne CD: The MOS 36-item short-form health survey (SF-36). I. Conceptual framework and item selection. Med Care 1992, 30:473-483.

69. Visser M, Goodpaster BH, Kritchevsky SB, Newman AB, Nevitt M, Rubin SM, et al: Muscle mass, muscle strength, and muscle fat infiltration as predictors of incident mobility limitations in well-functioning older persons. J Gerontol A Biol Sci Med Sci 2005, 60:324-333.

70. Villareal DT, Banks M, Siener C, Sinacore DR, Klein S: Physical frailty and body composition in obese elderly men and women. Obes Res 2004, 12:913-920.

71. Misic MM, Rosengren KS, Woods JA, Evans EM: Muscle quality, aerobic fitness and fat mass predict lower-extremity physical function in community-dwelling older adults. Gerontology 2007, 53:260-266.

72. Lajeunesse D, Pelletier JP, Martel-Pelletier J: Osteoarthritis: a metabolic disease induced by local abnormal leptin activity? Curr Rheumatol Rep 2005, 7:79-81.

73. Loeser RF: Systemic and local regulation of articular cartilage metabolism: where does leptin fit in the puzzle? Arthritis Rheum 2003, 48:3009-3012

74. Otero M, Lago R, Gomez R, Lago F, Gomez-Reino JJ, Gualillo O: Leptin: a metabolic hormone that functions like a proinflammatory adipokine. Drug News Perspect 2006, 19:21-26.

75. Otero M, Lago R, Gomez R, Dieguez C, Lago F, Gomez-Reino J, et al: Towards a pro-inflammatory and immunomodulatory emerging role of leptin. Rheumatology (Oxford) 2006, 45:944-950.

76. Schaffler A, Ehling A, Neumann E, Herfarth H, Tarner I, Scholmerich J, et al: Adipocytokines in synovial fluid. JAMA 2003, 290:1709-1710.

77. Ehling A, Schaffler A, Herfarth $\mathrm{H}$, Tarner $\mathrm{H}$, Anders $\mathrm{S}$, Distler $\mathrm{O}$, et al: The potential of adiponectin in driving arthritis. J Immunol 2006, 176:4468-4478

78. Olson TP, Dengel DR, Leon AS, Schmitz KH: Changes in inflammatory biomarkers following one-year of moderate resistance training in overweight women. Int J Obes (Lond) 2007, 31:996-1003.

79. Bassey EJ, Fiatarone MA, O'Neill EF, Kelly M, Evans WJ, Lipsitz LA: Leg extensor power and functional performance in very old men and women. Clin Sci (Lond) 1992, 82:321-327.

80. Bassey EJ, Short AH: A new method for measuring power output in a single leg extension: feasibility, reliability and validity. Eur J Appl Physiol Occup Physiol 1990, 60:385-390.

81. The ARIC investigators: The Atherosclerosis Risk in Communities (ARIC) Study: design and objectives. Am J Epidemiol 1989, 129:687-702.

82. Mazzuca SA, Hellio Le Graverand MP, Vignon E, Hunter DJ, Jackson CG, Kraus VB, et al: Performance of a non-fluoroscopically assisted substitute for the Lyon schuss knee radiograph: quality and reproducibility of positioning and sensitivity to joint space narrowing in osteoarthritic knees. Osteoarthritis Cartilage 2008, 16:1555-1559.

83. Zhang Y, Xu L, Nevitt MC, Aliabadi P, Yu W, Qin M, et al: Comparison of the prevalence of knee osteoarthritis between the elderly Chinese population in Beijing and whites in the United States: The Beijing Osteoarthritis Study. Arthritis Rheum 2001, 44:2065-2071.
84. Sharma L, Lou C, Cahue S, Dunlop DD: The mechanism of the effect of obesity in knee osteoarthritis: the mediating role of malalignment. Arthritis Rheum 2000, 43:568-575.

85. Duryea J, Neumann G, Niu J, Totterman S, Tamez J, Dabrowski C, et al: Comparison of radiographic joint space width with magnetic resonance imaging cartilage morphometry: analysis of longitudinal data from the Osteoarthritis Initiative. Arthritis Care Res (Hoboken) 2010, 62:932-937.

86. Washburn RA, Smith KW, Jette AM, Janney CA: The Physical Activity Scale for the Elderly (PASE): development and evaluation. J Clin Epidemio/ 1993, 46:153-162

87. McAuley E, Mihalko SL: Measuring Exercise-Related Self-Efficacy. In Advances in Sport and Exercise Psychology Measurement. Edited by Duda JL. Morgantown, W.V: Fitness Information Technology, Inc; 1998:371-389.

88. Laird NM, Ware JH: Random-effects models for longitudinal data. Biometrics 1982, 38:963-974.

89. Little RJA, Rubin DB: Statistical analysis with missing data. New York: John Wiley and Sons; 1987.

90. Wu MC, Bailey KR: Estimation and comparison of changes in the presence of informative right censoring: conditional linear model. Biometrics 1989, 45:939-955.

91. Conaway MR: Non-ignorable non-response models for time-ordered categorical response data. Applied Statistics 1993, 42:105-115.

92. Goodpaster BH, Chomentowski P, Ward BK, Rossi A, Glynn NW, Delmonico $\mathrm{MJ}$, et al: Effects of physical activity on strength and skeletal muscle fat infiltration in older adults: a randomized controlled trial. J Appl Physiol 2008, 105:1498-1503.

93. Albert MA, Danielson E, Rifai N, Ridker PM: Effect of statin therapy on C-reactive protein levels: the pravastatin inflammation/CRP evaluation (PRINCE): a randomized trial and cohort study. JAMA 2001, 286:64-70.

94. Ridker PM, Cannon CP, Morrow D, Rifai N, Rose LM, McCabe CH, et al: C-reactive protein levels and outcomes after statin therapy 1. N Engl J Med 2005, 352:20-28.

95. Sebestjen M, Keber I, Zegura B, Simcic S, Bozic M, Fressart MM, et al: Statin and fibrate treatment of combined hyperlipidemia: the effects on some novel risk factors. Thromb Haemost 2004, 92:1129-1135.

96. Bogaty P, Brophy JM, Noel M, Boyer L, Simard S, Bertrand F, et al: Impact of prolonged cyclooxygenase-2 inhibition on inflammatory markers and endothelial function in patients with ischemic heart disease and raised C-reactive protein: a randomized placebo-controlled study. Circulation 2004, 110:934-939.

97. Chan KY, Boucher ES, Gandhi PJ, Silva MA: HMG-CoA reductase inhibitors for lowering elevated levels of C-reactive protein. Am J Health Syst Pharm 2004, 61:1676-1681.

98. Canvin JM, el-Gabalawy HS: Anti-inflammatory therapy. Phys Med Rehabil Clin N Am 1999, 10:301-317.

99. Burr DB, Radin EL: Microfractures and microcracks in subchondral bone: are they relevant to osteoarthrosis? Rheum Dis Clin North Am 2003, 29:675-685.

100. Segal NA, Glass NA: Is quadriceps muscle weakness a risk factor for incident or progressive knee osteoarthritis? Phys Sportsmed 2011, 39:44-50.

101. Brandt KD, Heilman DK, Slemenda C, Katz BP, Mazzuca SA, Braunstein EM, et al: Quadriceps strength in women with radiographically progressive osteoarthritis of the knee and those with stable radiographic changes. J Rheumatol 1999, 26:2431-2437.

102. Amin S, Baker K, Niu J, Clancy M, Goggins J, Guermazi A, et al: Quadriceps strength and the risk of cartilage loss and symptom progression in knee osteoarthritis. Arthritis Rheum 2009, 60:189-198.

103. Messier SP, Legault C, Schoenlank CR, Newman JJ, Martin DF, Devita P: Risk factors and mechanisms of knee injury in runners. Med Sci Sports Exerc 2008, 40:1873-1879.

104. Schipplein OD, Andriacchi TP: Interaction between active and passive knee stabilizers during level walking. J Orthop Res 1991, 9:113-119.

105. Glitsch U, Baumann W: The three-dimensional determination of internal loads in the lower extremity. J Biomech 1997, 30:1123-1131.

106. McAlindon TE, Snow S, Cooper C, Dieppe PA: Radiographic patterns of osteoarthritis of the knee joint in the community: the importance of the patellofemoral joint. Ann Rheum Dis 1992, 51:844-849.

107. Cicuttini FM, Baker J, Hart DJ, Spector TD: Association of pain with radiological changes in different compartments and views of the knee joint. Osteoarthritis Cartilage 1996, 4:143-147. 
108. Laskin RS, van Steijn M: Total knee replacement for patients with patellofemoral arthritis. Clin Orthop Relat Res 1999, 367:89-95.

109. Guermazi A, Eckstein F, Graverand-Gastineau M-PHL, Conaghan PG, Burstein D, Keen $\mathrm{H}$, et al: Osteoarthritis: current role of imaging. In Medical Clinics of North America. Edited by Hunter DJ. ; 2009:101-126.

110. Gerber TC, Carr JJ, Arai AE, Dixon RL, Ferrari VA, Gomes AS, et al: lonizing radiation in cardiac imaging: a science advisory from the American Heart Association Committee on Cardiac Imaging of the Council on Clinical Cardiology and Committee on Cardiovascular Imaging and Intervention of the Council on Cardiovascular Radiology and Intervention. Circulation 2009, 119:1056-1065.

doi:10.1186/1471-2474-14-208

Cite this article as: Messier et al: Strength Training for Arthritis Trial

(START): design and rationale. BMC Musculoskeletal Disorders 2013 14:208.

\section{Submit your next manuscript to BioMed Central and take full advantage of:}

- Convenient online submission

- Thorough peer review

- No space constraints or color figure charges

- Immediate publication on acceptance

- Inclusion in PubMed, CAS, Scopus and Google Scholar

- Research which is freely available for redistribution 